\title{
BUILDING VIRTUAL PROFESSIONAL
} COMMUNITIES

\author{
Bernhard R. Katzy, Gordon Sung \\ CeTIM - Center for Technology and Innovation Management at University BW Munich \\ Prof.Katzy@CeTIM.org, Gordon.Sung@CeTIM.org
}

GERMANY

\begin{abstract}
Professionals exploit professional knowledge, which they create in communities. These communities are often distributed and typically meet during regular events to further their community development, exchange their expertise. Virtual professional communities could use the Intermet as their cooperation platform, which intuitively looks like the technological ideal match for the networked organizational structure of professional communities. However, the take-up of Internet technology is still slow. In this paper we develop a model to explain how virtual professional communities can be created, organized and managed in such a way that the perceived value of membership becomes a driver for community development. We will illustrate our model with the case of the "Virtual Organization Forum" from which we derive seven critical factors for successful building a virtual professional community.
\end{abstract}

\section{INTRODUCTION}

Professional communities provide environments for professionals to share the body of knowledge of their professions such as similar working cultures, problem perceptions, problem solving techniques, professional values, and befitting behavior. Examples of well-established communities are IEEE, IFIP, and IFAC, just to name a few. To share similar education and many years of comparable working experience provide a basis of mutual understanding and trust among professionals regardless of their geographical location or affiliation. Existing professional communities have traditional membership and governance mechanisms. These secure professional quality standards and the development of the professional community. For example, there are typically strict rules for peer reviewing new knowledge, which guarantees the reliability and high quality of the professional knowledge.

Today's fast emerging information communication technologies have stimulated virtual communities to grow using the World Wide Web. The development of the computer system Linux, for example, is almost entirely based on virtual cooperation of professionals. Due to their professional background, similar interests, and inherited trust virtual professional communities seem an ideal match between organizational need and emerging new technology. Yet, the take-up of virtual professional communities is slower than could be expected.

In this paper we explore what managerial and organizational approach is needed to ensure the functioning of virtual professional communities. How is growth and interests of community members sustained and knowledge transferred? To the

The original version of this chapter was revised: The copyright line was incorrect. This has been corrected. The Erratum to this chapter is available at DOI: 10.1007/978-0-387-35585-6_68 
academic community this paper contributes insights on how virtual organizations and virtual communities are built. To professionals this paper contributes critical success factors for web-enabled working.

The reminder of the paper is structured as follows. First we review existing literature in the area of virtual organizations and virtual communities. We then describe our process model for building virtual communities and illustrate it with the "Virtual Organization Forum". We conclude with a short discussion of the case and critical success factors for web enabled working in virtual communities.

\section{VIRTUAL ORGANIZATION, VIRTUAL COMMUNITY, AND KNOWLEDGE MANAGEMENT}

In this chapter we review the three concepts: virtual organization, virtual community and knowledge management with the objective to contribute to understanding the virtual professional communities.

\subsection{Virtual Organization}

The concept of virtual organization centers on the ability to quickly come to new operational configuration from a larger network of potential partners. This ability to rapidly 'switch' (Mowshowitz, 1997) between partners for business opportunities leads to flexible or 'agile' (Goldman et. al., 1995) business behavior. For our purpose we adopt the following definition of virtual organization:

"The virtual organization is based on the ability to create temporary co-operations to realize the value of short business opportunity that partners cannot capture on their own" (Katzy \& Schuh, 1998)

This definition expresses a management principle rather than a description of an organizational form. Professional communities allow creating operative projects in response to customer requests, which are jointly executed by specialists and experts who rally for the limited lifetime of the project. The challenge of virtual organizing is to allocate resources when no pre-existing hierarchy is available and decisionmaking is undertaken amongst a group of peers or independent professionals. Such decision processes require a sophisticated infrastructure, a network.

\subsection{Virtual Community}

Virtual communities are defined as social systems of networks of individuals, who use computer technologies to mediate their relationships. The focus here is less on activities or projects, but on the social system.

"A Virtual community is a computer-mediated social group which is based on the belief that humans are social creatures and that communities enable socializing. A virtual community is the technological response to this inherent human need." (Sudweeks \& Rafaeli, 1996)

Neither technology, nor sociality can substitute for each other. Therefore, virtual communities need to consist of two interrelated constitutional elements, the association of members, and an enabling medium. According to Schmid (2000), common features of all virtual communities are: common interests, shared practices 
and languages with common semantics, and normative issues. They are based on trust and commitment (Wenger \& Snyder, 2000), and thus build on loyalty between the participants (Schubert, 2000). Overall, professional communities do show the characteristics of the above definition with a specific focus on generating professional knowledge.

\subsection{Knowledge Management}

Knowledge management is considered as the major competitive advantage of organizations (Nonaka \& Takeuchi, 1996, Davenport \& Prusak, 1998 and Senge, 1993). Following Alavi and Leidner (1999) skilled individuals - professionals in our context - are essential to turn information into knowledge, and vice versa to turn knowledge into information to articulate and communicate it. While most research was concerned with individuals inside integrated organizations, this process is equally applicable to professional communities.

The distinction between tacit (personal, context-specific) and explicit knowledge (transmittable in formal, systematic language) (Polanyi, 1966) points to potential limits of virtual communities. The virtual part can be expected to best support the exchange of explicit knowledge, while complementary means are needed for the exchange of tacit knowledge.

All three concepts knowledge management, virtual organization and virtual community share the process oriented understanding of organizational phenomena, which we will use in the following section for the development of our model of building virtual professional communities.

\section{A PROCESS MODEL FOR CREATING A VIRTUAL PROFESSIONAL COMMUNITY}

We use the avalanche metaphor of growth that is initiated by a small core-group and multiplied into a movement as a general pattern community development. The creation of new knowledge requires high levels of trust, care and personal relationships (Roos \& Krogh, 1996; Swan, Newell et al., 2000), which is best accommodated in small groups. The diffusion of knowledge requires a social system (Figure 1).

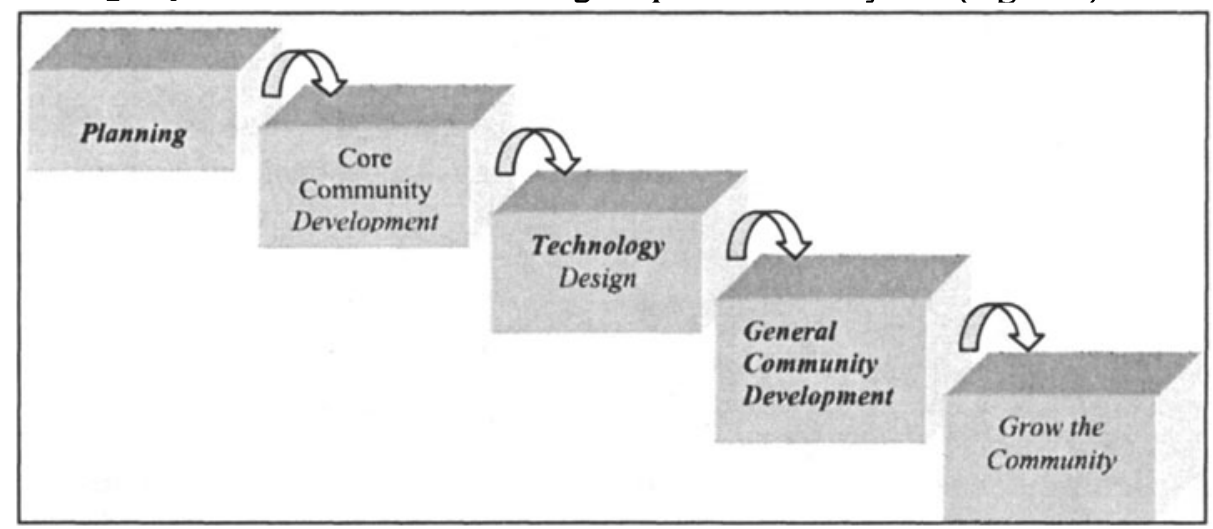

Figure 1 - Process model for creating a virtual professional community 


\subsection{Planning}

Prior to building a virtual professional community, an initial core group needs to be in place. This (virtual) group establishes the facilitating entity, the initial provider of meaning, and the catalyst or the stimulant.

\subsection{Core community development}

The next stage is to form the core community. The objective of the core community is to gather and organize a group of "builders" for the community. This core group has the responsibilities to facilitate the creation of shared meaning, produce new ideas, make already existing ideas available for a wider audience, and also provide the intellectual and social leadership for the community. Active participation of the core group attracts new members to join.

\subsection{Technology design}

A successful community needs to have a flexible and complementary coupling between technical and social elements (Wenger \& Snyder, 2000). The role of technology in this context is to overcome spatial distance to achieve social cohesion. Schmid (2000) has identified main aspects of the technical structure:

- The domain of discourse as the base for common language and meaning.

- Identification and modeling of the participating agents in terms of beliefs, intentions, desires, capabilities and preferences.

- Identification and modeling of roles and processes applied by the community

- Identification and modeling of applied communication patterns.

\subsection{General community development}

In order to sustain the continuing growth of the community, getting critical mass of member is the primary task for extending the existing community to a wider community. Hagel and Armstrong (1997) have identified three gates to highlight the challenges for getting the critical mass of the member group:

- Generating traffic. (Get target community members to travel to your site.)

- Concentrating traffic. (Make them to spend increasing time in the community.)

- Locking in traffic. (Create switching barriers to other communities)

\subsection{Grow the community}

The finial stage of the community building process is to maintain on-going events. Careful grouping of events according to their life cycle stages will facilitate the process of cross event comparison. Organizing discussions seems to be an effective way to extract the knowledge from each individual and to share among others, and knowledge databases can be used as a measurement for the achievement of community to date. 


\section{THE CASE OF VIRTUAL ORGANIZATION FORUM}

The NECTAR - Virtual Organization Forum was a first cluster project of the European Commission, aiming at the creation of synergies among professionals within the Telematics Application Programmes of European research. Professionals were Europe-wide distributed and involved in more than 40 concurrent R\&D projects. All experts were selected because their work was related to the concept of 'virtual organizations', which has been the domain of the intended community. In the words of the above described process model, the Virtual Organization Forum did deploy a number of instruments to achieve its objective in the period from summer 1997 until February 2001.

Planning was undertaken in a small group of four experts who were paid by the European Union for this work as 'moderators'. In the next step the Virtual Organization Forum organized around four workshops hosted by the EU. The aim of the physical workshops was to bring together the core-group. Participants were managers, consultants in the field and academics of various disciplines, ranging from information systems, manufacturing and operations to organizational theorists who are actively searching for explanations and prescriptions of solutions. The workshops were intended to help defining new research topics and potentially lead to the development of new research projects.

Technology was designed and deployed to build a virtual professional community. Two electronic discussion groups were established. Both of them were used to collect information as input for further physical workshops. Further, a web portal under the name of www.VE-Forum.de was launched.

By summer 2000 funding for the community expired and no further activities were undertaken. By mid of 2001 some experts re-established funding and activity showing that the community had not dissolved but had turned towards other places where better support was granted.

\section{CRITICAL FACTORS FOR OPERATING A VIRTUAL PROFESSIONAL COMMUNITY}

In this chapter we discuss critical success factors for virtual professional community development. Given the early state of research, it would be impossible to predict success. We therefore turn our argument around and list those factors, whose lack did limit the evolution of www.VE-forum.de.

\subsection{Domain Choice}

A virtual professional community in the domain of virtual enterprises at that time was an ambiguous choice because the concept only was in an emerging state driven by researchers from multiple disciplinary backgrounds, such as computer science, organizational science, or industrial engineering. Diversity within the core community and an initial absence of shared knowledge and accepted scientific standards limited the development of the virtual professional community. 


\subsection{Organizing the Community}

The success of a virtual professional community is limited to the degree of precision in organizing that it can create. In the case of the virtual enterprise forum, potential new entrants to the virtual professional community applied for membership long after www.VE-forum.de had disbanded. Without organizing core, however, no new activities were initiated and did not develop. This is some how in line with the literature that a virtual community has to have a clearly defined organizational structure, and together with a detailed description of possible roles (StanoevskaSlabeva \& Schmid, 2000). The virtual enterprise forum defined two roles. A community membership was granted to those who subscribed to the web page and were accepted by the moderators. The funding body granted membership of the virtual core team.

\begin{tabular}{|l|l|l|}
\hline Dimension / factor & Virtual community & (Virtual) Core Team \\
\hline Objectives/Purpose & Individual & Communal \\
\hline Relationship & Informal & Interdependence \\
\hline $\begin{array}{l}\text { Role of } \\
\text { Management }\end{array}$ & $\begin{array}{l}\text { Infrastructure, motivate } \\
\text { members and cultivate. }\end{array}$ & $\begin{array}{l}\text { Design, implementation and } \\
\text { authority }\end{array}$ \\
\hline Incentives & External and personal & Funding based \\
\hline Membership & Self selected & by the process Owner \\
\hline
\end{tabular}

Table 2: Dimension difference between (virtual) core team and virtual community

\subsection{Member Relationships and Community Objectives}

A perceived limitation to gaining credibility was that the community did not legitimate the core team; an external funding body instead installed it. Success of a virtual professional community is limited by the transparency of relations and objectives it can create for its participants. When funding expired for the core group, the forum lost its essential support.

\subsection{Community Management}

The success of a virtual professional community is limited by the availability of management resources. Communities do have a democratic nature as a mode in which professionals interact and organize themselves. It means that they set their own agenda and organize their own leadership. In other words, they benefit from cultivation (Wenger \& Snyder, 2000), which was provided in form of external funding. The virtual enterprise forum developed several "classical" management functions for which resources were available throughout its lifespan.

\subsection{Incentives}

Success of a virtual professional community is limited by the perceived incentives to participate. Communities are vulnerable because they lack the legitimacy and budgets of established organizations. Monetary incentives in the case of the virtual enterprise forum were a short-term option. The forum was quickly created, but only existed as long as funding was provided; on the web incentives were purely personal. People participate because they felt they benefit by doing it. That might be 
through knowledge, social relationships, personal growth, appreciation or other intangibles. The virtual organization of the core team was closer to a "normal" enterprise in this sense, because it was based on funding

\subsection{Membership}

The success of a virtual professional community is limited by the quality of members selected. In www.Ve-forum.de members were self-selected. People were invited to join, and end up joining based on a gut sense of appropriateness (Wenger \& Snyder, 2000). www.Ve-forum.de enjoyed participation of accepted professionals and kept its reputation as a serious professional community. It did not face the experience of other communities that too many young or too low qualified professionals joined and ruined the attractiveness for senior professionals.

\subsection{Knowledge Management}

Success of www.Ve-forum.de depended on the ability to share, exchange and create knowledge. Overall, a virtual professional community is limited by the knowledge services it can provide to its members.

The virtual enterprise forum had limited success in creating knowledge. Indexing, key words, and keyword in context (KWIC) combined with search mechanisms were intended means to facilitate individual for searching the information and gaining knowledge. However the majority of the members did not accept classifications and keywords, which can readily be attributed to the early stage of concept development. As a consequence explicit knowledge transfer was limited. Instead www.Ve-forum.de provided a sort of 'yellow pages' to facilitate direct contact between community members. Discussion groups proved to be a further feasible solution for extracting this tacit knowledge.

\section{CONCLUSION}

In this paper, we have explored possibilities for creating, managing and organizing a virtual professional community. Based on the literatures of virtual organization, virtual community and knowledge management we have sharpened the understanding of the specifics of virtual professional communities. We have forged our findings into a process model for building virtual professional communities. Finally, we described the challenges of creating and maintaining a virtual professional community with the case of the www.Ve-forum.de. Based on the lessons learnt we derived critical success factors for web enabled working in virtual communities.

In a nutshell, the conducted research points to the old foundations of organizations, communities and organizations (bureaucracy in the words of Weber, 1947), which need to be redeveloped to make use of new possibilities of the emerging information infrastructures.

In our paper, virtual communities represent the community aspect of organizations. Virtual organizations for the core team address the need for efficient processes in a new, more distributed way. Virtual professional communities, as we 
have discussed them here, point to the complementarity of both community and organization. A third element, the increased importance to rapidly switch project partners from business opportunity to business opportunity, is new in the information society. Further research will be necessary to explain, why some virtual professional communities are successful and others fail. This research will need to take emerging infrastructures into account (e.g. broadband applications), which allow for increasingly media-rich communication channels and better community building.

\section{REFERENCES}

1. Alavi, M., D. Leidner (1999): Knowledge Management Systems: Emerging Views andPractives form the Field. 32nd Hawaii International Conferance on System Sciences, Hawaii.

2. Armstrong, A., J. Hagel (1996): The real value of on-line communities, Harward Business Review May-June.

3. Davenport, T. (1998): Succesful knowledge management projects, Sloan Management Review(Winter 1998): 443-57.

4. Davenport, T., L. Prusak (1998): Working Knowledge. Boston, Massachusetts, Harward Business School Press.

5. Goldman, S.L., Nagel, R.N., Preiss, K. (1995): Agile Competitors and Virtual Organizations - Strategies for Enriching the Customer, Van Nostrand Reinhold, New York.

6. Hagel, J., A. G. Armstrong (1997): Net Gain, Harward Business School Press.

7. Katzy, B., G. Schuh (1998): The Virtual Enterprise. Handbook of life cycle engineering: Concepts, tools and techniques, A. M. Gutierrez, J. M. Sanchez and A.

8. Mowshowitz, A. (1997): Virtual Organization, Communications of the ACM, Vol. 40, No. 9, p. 30-37

9. Nonaka, I.., H. Takeuchi (1996): The knowledge creating company, Oxford, Oxford University Press.

10. Polanyi, M. (1966): Personal Knowledge: Towards a post-critical philosophy. New York, Harper Torchbooks.

11. Roos, J., G. v. Krogh (1996): The epistemological challenge: Managing knowledge and intellectual capital, European Management Journal 14 (4).

12. Senge, P. (1993): The fifth discipline, Business (Century/Arrow).

13. Stanoevska-Slabeva, K. and B. F. Schmid (2000): A Generic Architecture of Community Supporting Platforms based on the Concept of Media. The 33rd Hawaii International Conference on System Sciences - 2000, Hawaii.

14. Sudweeks, F. and S. Rafaeli (1996): How do you get a hundred strangers to agree: Computer mediated communication and collaboration. Computer Networking and Scholarship in the $21^{\text {st }}$ Century University. T. M. H. a. T. D. Stephen, SUNY Press.

15. Swan, J., S. Newell, et al. (2000): When will people management enter the debate? the $33^{\text {rd }}$ Hawaii International Conference on System Sciences - 2000, Hawaii.

16. Wenger, E. and W. Snyder (2000): Communities of practice: The organizational Frontier, Harward Business Review 78 (1). 